\title{
Usage of Smartphone Applications: A Descriptive Study of Top 100 U.S. Retailers
}

http://dx.doi.org/10.3991/ijim.v10i3.5827

\author{
W. Koo \\ Western Illinois University, Macomb, USA
}

\begin{abstract}
The study investigated how top 100 U.S. retailers use their smartphone applications. Based on the literature, the study found five major functions of smartphone applications: content delivery, transaction, promotion, location service, and entertainment. Descriptive and frequency analyses revealed actual usage of the five functions among the top 100 U.S. retailers. Detailed implications for marketers were discussed based on the findings.
\end{abstract}

Index Terms-Mobile applications; mobile commerce; retailing; smartphones

\section{INTRODUCTION}

The emergent of the mobile phone opened a new transactional area in which consumers can run away from their personal computers [1]. There were about 3.6 billion mobile subscribes (i.e., the $40 \%$ penetration rate) by end of 2014 globally [2]. The penetration rate is expected to grow about $60 \%$ by 2020 [2]. As the exponential growth of the mobile phone, mobile commerce (m-commerce) has been received a lot of attention [1].

M-commerce has distinctive features in comparison with e-commerce, such as always-on features, locationbased services, customization, and so on [3]. In line with high usage and particular advantages of m-commerce, $\mathrm{m}$ commerce has been in the outrageous growing stage. Global m-commerce sales would record $\$ 626$ billion in the early year of 2018, which would be about $207 \%$ growth as compared with 2014 [2].

The smartphone, a technologically advanced mobile phone, emerged in 2006 [4]. Because of consumers ' unfamiliarity, the smartphone occupied the $5 \%$ of global mobile market in the beginning of 2009; however, there were already 2.6 billion smartphone users worldwide, and the users are expected to grow about by 5.9 billion by the end of 2020 [5]. Among developed countries, the penetration rate of smartphones have already recorded about $60 \%$, and the penetration rate is expected to reach about $80 \%$ within next four years.

With the huge growth, smartphones contain greatly advanced technologies such as power efficient processors, broadband internet access with full browsing features, the global positioning system, and so on. These advanced technologies can overcome limitations of prior multimedia phones having low screen resolution, very restricted Internet functions, and so on. Accordingly, the smartphone can be widely used for commercial purposes with advanced approaches. Business practitioners are already anticipated the power of smartphone for the commercial purposes.

Nevertheless, so far, the use of smartphone applications (hereafter, apps) has been overlooked by a great number of small and large retailers. Thus, the goal of this study is to investigate the current use of the smartphone apps among the top 100 U.S. retailers so that the study can suggest clear directions to use smartphone apps for small and large business practitioners.

\section{LITERATURE REVIEW}

\section{A. Mobile Commerce (M-Commerce)}

All direct or indirect transactions with monetary value through a wireless telecommunication network can be defined as $\mathrm{m}$-commerce [6]; in addition, since types of the $\mathrm{m}$-commerce transactions are similar to electronic commerce (e-commerce), some scholars just call m-commerce as "wireless e-commerce" [7]. Considering the two definitions, m-commerce is pertinent to sorts of the network rather than devices. Namely, not only mobile phones, but also all devices that use a wireless telecommunication network can be m-commerce devices such as personal digital assistants (PDAs), ultra-mobile personal computer (UMPC), portable gaming devices, and so on. Ecommerce uses a broadband network service rather than a wireless telecommunication network service. Therefore, although computers can use Internet wirelessly, it cannot be considered as m-commerce. M-commerce has been, therefore, developed along with technological development of a wireless telecommunication network.

\section{B. Development of Wireless Telecommunication Networks and M-commerce Services}

Around 1980, the first generation (1G) mobile communication systems emerged [8]. In the $1 \mathrm{G}$ network, wireless services supported an analogue signal which can transfer the voice only. The beginning and development of $\mathrm{m}$ commerce emerged with the $2 \mathrm{G}$ (TDMA) network during the 1990s [8]. The 2G network which is also called global system for mobile communications (GSM) was revolutionary development from $1 \mathrm{G}$ with regard to the availability of data transfer. GSM enabled slow data transmission (e.g., $9.6 \mathrm{kbps}$ ) through the telecommunication network. Namely, the $1 \mathrm{G}$ analogue system was changed to the digital system in GSM. Although the speed of the data transfer was slow, simple promotional messages sent via text messaging were possible in this stage. With the advent of multimedia phones which embody a simple Internet browsing function, mobile Internet access services were also available in the $2 \mathrm{G}$ network. i-Mode and Wireless Application Protocol (WAP) were representative Internet services using the $2 \mathrm{G}$ network. The i-Mode service was provided in Japan, but the WAP service was dominant in other countries including the United States. 
The advent of $3 \mathrm{G}$, universal mobile telecommunication system (UMTS), accelerated the growth of m-commerce. UMTS had a capability of remarkably fast data transfer rates (e.g., up to 2Mbps) [9]. Accordingly, high quality images and video can be delivered through the multimedia phones in real time. New m-commerce services were also opened such as mobile banking, news subscriptions, mobile ticketing, and visually enhanced mobile websites. However, multimedia phones' websites could not embody full PC version websites.

\section{Smartphone}

The smartphones are the most advanced mobile phones, and are currently in the strong growing stage especially in the United States [10]. There are many advanced functions in the smartphone in comparison with the multimedia phone, such as a larger display with high screen resolution, the QWERTY (same as a computer keyboard) input system, global positioning system (GPS), and so on. Furthermore, the smartphone contains four exclusive features: central processing unit (CPU), operating system (OS), WiFi connectivity, and full Internet browsing. Namely, a generation of ubiquitous computing has arrived due to the advent of the smartphone [11]. As personal computers, smartphones have infinite development potentialities in that the smartphones can embody uncountable small programs called apps made by a number of programmers. Not only that, consumers can experience full PC version websites. Consequently, the smartphone destroyed technological boundaries between the PC and mobile phone. Consumers have truly been able to experience full electronic commerce features wirelessly.

\section{Smartphones in M-Commerce}

According to Gartner's research, during a year, mcommerce transactional value increased about $12.7 \%$ in the first quarter of 2009 as more people were buying smartphones [12]. Despite these enormous advantages, many retailers are still staying in e-commerce or traditional m-commerce with multimedia phones because of newness of the smartphone.

The most growing smartphone activity is shopping; starting from 2008, several retailers (i.e., Amazon, Marriott International, Barnes \& Noble, CVS, Sears, etc.) have begun to utilize the smartphone for their business in two representative ways: mobile-friendly websites and providing own apps [12].

\section{1) Mobile friendly websites}

Technologically the smartphone is able to support full PC version websites. However, since the smartphone has small screen sizes and relatively slow Internet connection speed that cannot well support high quality websites features (e.g., graphic, video clips, Flash, etc.) of full PC version websites. To overcome the limitations of the smartphone, business practitioners establish mobile version of their websites in which several functions and categories are excluded. For instance, mobile friendly websites use fundamental HTML tags, small layout, and low quality graphic, and keep away from plugins and Javascripts [13].

\section{2) Providing own apps}

Downloading apps is the dominant and frequent activity among smartphone users. Approximately 59\% of smartphone users replied that they downloaded at least one app within a month [14]. Consumers download a wide range of apps such as games, weather information, social networking, navigation, and so on. Although those apps are not related to retailers, the apps are used for the purpose of advertising tools. Retailers offer their advertisements in the starting point of apps. Not only that, recently, retailers are releasing their own apps for diverse marketing purposes.

\section{E. Essential Functions of Apps for M-Commerce}

Browsing merchandise, transactions, and promotions are considered as essential functionalities of online stores [15]. In addition, in the case of online stores for retail chain stores, a store locator function should be evaluated [16].

Smartphone apps for m-commerce can be regarded as wireless online stores. Accordingly, as scholars evaluate functionalities of the smartphone apps and mobile-friendly websites, core functionalities of online stores should be considered.

"Ref. [17]" found several major attributes of $\mathrm{m}$ commerce apps: content delivery, transaction, location service, and entertainment.

Combining all functions found from previous studies [3, 15,16 , and 17], core functions of smartphone apps for $m-$ commerce can be classified as followings:

- Content delivery - Providing necessary information for consumers such as product information, company information, news, etc.

- Transaction - Providing full transactional functions with the capability to do payment

- Promotion - Announcing sales promotions or events

- Location service - Receiving services based on recognizing a location through the GPS function of a smartphone such as the store locator, location based deals, etc.

- Entertainment - Offering additional services providing entertaining experiences such as bar/QR code scanners, games, etc.

Beyond traditional brick-and-mortar pure players, multi-channel strategies have been widely adopted by a majority of retailers [18]. A significant change in the multichannel environment in these days is that borders among multiple channels have been eliminated. For instance, consumers search information in one channel, and purchase product in another channel [18]. Thus, multichannel retailers do not provide same uncountable functions across all their possible channels. Rather, they highlight core functions in a specific channel so that consumers can easily use core functions of the channel without pressure caused by complex and overwhelming functions.

By understanding core functions in smartphone apps of top 100 U.S. retailers, the study can know how top retailers use the smartphone apps in the recent multi-channel retail environment. The findings can be also used to provide specific directions to develop smartphone apps for retail purposes. Thus, the following research question is proposed:

Which functions (i.e., content delivery, transaction, promotion, location service, and entertainment) are available in smartphone apps of top 100 U.S. retailers? 


\section{METHODOLOGY}

This chapter describes the methodology for this study including sampling and statistical analyses of the data.

\section{A. Population and Sample}

The population for this study is all sorts of retailers in the United States. The study used the top 100 U.S. retailers announced by NRF STORE offering authoritative rankings [19]. The top 100 retailers chosen in accordance with their annual revenues [19], implying that top 100 retailers can be in the good financial performance due to their diverse and creative marketing efforts. Namely, the study anticipated that the results can offer creative and valuable insight to scholars and retailers for successful business.

\section{B. Data Collection}

The data were collected via iPhone in February 2016. The reasons of selecting iPhone for the data collection was that iPhone was in the dominant position with regard to data usage in the United States [20]. In addition, iPhone offers an exclusive download interface for apps: App Store.

As the research question describes, this study examines how top 100 U.S. retailers offer core functions (i.e., content delivery, transaction, promotion, location service, and entertainment) in their smartphone apps.

To find apps offered by the top 100 U.S. retailers, the study typed retailers names in a search box in a search menu of App Store. If an app did not appear, the study searched some alternative names of a retailer. If the study yet could not find the app, the study visited the retailer's website to ensure the app is not offered by the retailer. After fully experiencing all functions in apps, the study marked on relevant functions provided in apps. Since apps can contain diverse entertainment functions, the study made short descriptions if interesting entertainment functions were found.

\section{Statistical Anaysis}

The Statistical Package for Social Science (SPSS) version 22.0.0 was used for the statistical analyses. Descriptive and frequency analyses were conducted to demonstrate a specific percentage of each smartphone function.

\section{RESULTS}

Among top 100 U.S. retailers, 81 retailers provided their own apps in App Store. When it comes to functions available in apps, the most commonly provided function was the location service $(93.8 \%)$ followed by content delivery $(87.7 \%)$, promotion $(75.3 \%)$, transaction $(54.3) \%$, and entertainment (53.1\%). See Table I.

As for specific entertainment functions, scanning $(67.4 \%)$ and shopping list $(39.5 \%)$ functions were most common. See Table II.

Few retailers offered unique entertainment functions suitable for their business. Unique entertainment functions are listed in Table III.

\section{DISCUSSION}

This study examines how smartphones, the most technologically advanced mobile devices, are currently used by top 100 U.S. retailers as a business tool. The top 100 U.S. retailers are selected for the analyses because they
TABLE I.

CORE FUNCTIONS IN APPS

\begin{tabular}{lccc}
\hline & \multicolumn{3}{c}{ Apps } \\
\cline { 2 - 4 } & $\boldsymbol{N}$ & $\mathbf{( \% )}$ & Total \\
\hline Content delivery & 71 & $(87.7)$ & 81 \\
\hline Transaction & 44 & $(54.3)$ & 81 \\
\hline Promotion & 61 & $(75.3)$ & 81 \\
\hline Location service & 76 & $(93.8)$ & 81 \\
\hline Entertainment & 43 & $(53.1)$ & 81 \\
\hline
\end{tabular}

TABLE II

ENTERTAINMENT FUNCTIONS

\begin{tabular}{llll}
\hline & \multicolumn{3}{c}{ Apps } \\
\cline { 2 - 4 } & $\boldsymbol{N}$ & (\%) & Total \\
\hline $\begin{array}{l}\text { Scanner } \\
\text { (Barcodes or QR codes) }\end{array}$ & 29 & $(67.4)$ & 43 \\
\hline $\begin{array}{l}\text { Shopping list } \\
\text { (A list of products needed to be pur- } \\
\text { chased) }\end{array}$ & 17 & $(39.5)$ & 43 \\
\hline
\end{tabular}

TABLE III.

UNIQUE ENTERTAINMENT FUNCTIONS

\begin{tabular}{ll}
\hline \multicolumn{1}{c}{ Unique functions } & \multicolumn{1}{c}{ Names of retailers } \\
\hline $\begin{array}{l}\text { Book cover scanner (identifying a book } \\
\text { by taking a photo of a book cover) }\end{array}$ & Barnes \& Noble \\
\hline $\begin{array}{l}\text { Color code finder (finding color codes } \\
\text { from pictures) }\end{array}$ & Sherwin-Williams \\
\hline Live chat & The Home Depot \\
\hline $\begin{array}{l}\text { Mobile wallet (generating a QR code } \\
\text { for quick payment) }\end{array}$ & Neiman Marcus \\
\hline $\begin{array}{l}\text { Photo center (editing and ordering } \\
\text { photos) }\end{array}$ & Costco; Meijer; Walgreen \\
\hline $\begin{array}{l}\text { Toolbox (caliper, converter, nut \& bolt } \\
\text { finder, etc.) }\end{array}$ & Menard; The Home Depot \\
\hline $\begin{array}{l}\text { QVC TV live (streaming live TV home } \\
\text { shopping) }\end{array}$ & QVC \\
\hline
\end{tabular}

can maintain their top positions due to their innovative strategic development and financial capability to develop new technological strategies.

The results indicate that among the top 100 U.S. retailers, the majority of retailers (81 out of 100) provide their own smartphone apps, implying that the top U.S. retailers understand benefits of offering their own smartphone apps although developing and managing apps are costly.

The critical benefit of smartphone apps is that smartphone apps can provide better user experience than mobile version websites because apps can use best interfaces and functions for a specific retailer instead of using limited interfaces and functions in mobile web browsers [21].

Despite the abovementioned benefits, still the mobile apps do not show the perfect penetration rate even among the top 100 U.S. retailers. The results may come from unfamiliarity of new ways of using the smartphone as a marketing tool. Retailers surely recognize that the mobile phones are useful tools for the marketing purposes, and, in fact, they are already using the mobile phones for diverse ways such as advertising, shopping, billing, and so on. However, the retailers may not try to seek new possible ways of using the smartphone. 
PAPER

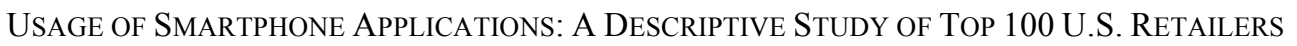

Another reason could be that there is no proven successful outcome derived from establishing their own smartphone apps. Although the retailers recognize the new ways of using the smartphone, the retailers would not easily invest a large amount of budgets in establishing smartphone apps due to high risks.

The study also identified core functions available in smartphone apps based on literature review as followings: content delivery, transaction, promotion, location service, and entertainment.

Among 81 top U.S. retailers offering their own smartphone apps, $76(93.8 \%)$ retailers offered location services. The exclusive advantages of mobile devices that cannot be found in traditional computers is ubiquity (i.e., anytime anywhere availability) [11], and top U.S. retailers take full advantage of it by providing location services in diverse ways. Since the top U.S. retailers have a great number of stores nationwide, they mainly use the location service to find stores near consumers. In addition, exclusive promotions that can be used in near stores are also offered based on the location service.

The second major function offered in smartphone apps was content delivery. $76(87.7 \%)$ retailers use their smartphone apps to deliver diverse information. One remarkable fact is that a majority of retailers do not provide general company information via smartphone apps such as company history, goals, and corporate social responsibility (CSR) activities. Rather, they focus on providing information relevant to actual transactions such as product information, services, and terms. The U.S. retailers do understand that the small screen size is not appropriate for providing long and detailed company and CSR information.

The third widespread function was promotion, and 61 (75.3\%) top U.S. retailers offered promotions via their smartphone apps. Promotions provided in apps contain huge advantages. Compared with mobile-friendly websites, smartphone apps can offer promotions made with high-quality image, audio and video because apps are somewhat free from loading time. Promotions are presented in diverse ways. Promotions are usually presented in the starting page, and some promotions are presented during the loading time before entering the main menu; in addition, some retailers assign promotional menus to the main menu or navigation bar.

Transaction was the fourth place function in smartphone apps. Since top U.S. retailers understand the advantages of providing the transactional function in smartphone apps, $44(54.3 \%)$ retailers already offer the transactional function. However, still almost half of the. retailers do not provide the transactional function in their smartphone apps.

This outcome can be explained by relatively weak security systems in smartphone apps [22]. Security systems for smartphone apps are as much strongly developed as those in online stores. Although Apple insists that they allow apps only in the case of passing their own security tests, consumers can download apps from different external roots. Those apps can contain harmful Trojan Horse which can incur loss of data and stealing personal information [23].

Instead of providing the transactional function within smartphone apps, some smartphone apps provide link to the full online stores (i.e., mobile version of online stores) to process transactions in traditional online stores. However, retailers should provide the transactional function within a smartphone app for customer convenience which is the critical advantage of mobile apps [3]. Once consumers are directed to mobile version of online stores (i.e., a mobile web browser will open mobile version of online stores) to finish transactions, they should be hard to come back to smartphone apps again.

Next, only about half of smartphone apps (53.1\%) provided some entertaining functions, demonstrating that top U.S. retailers have somewhat overlooked providing entertaining functions in their smartphone apps. An external camera in a smartphone was widely used by top U.S. retailers to provide entertaining functions in their smartphone apps. The barcode and QR code scanners were the most common entertaining functions. In line with that few retailers offered some advanced scanning functions. Barnes \& Noble offered a book cover scanner that identifies a book by taking a photo of a book cover instead of scanning barcodes or QR codes. Sherwin-Williams offered a so-called color code finder that can find specific color codes in pictures. The shopping list was the next common entertaining function. Consumers can make shopping lists in the smartphone apps; otherwise, they can open existing shopping lists in their Internet accounts. The two most widely used entertaining functions (i.e., scanners and shopping lists) well take advantage of mobility of smartphones in that consumers will use scanning and shopping list functions while they are shopping.

There were some unique entertainment functions. For instance, as Table 3 demonstrates Neiman Marcus offered a so-called mobile wallet function that allows consumers to generate a QR code which can be scanned by cashiers for enabling a quick payment. Some retailers offered unique entertaining functions that well fit into their business. For instance, home improvement retailers such as The Home Depot and Menard offered toolbox functions that provide virtual calipers, converts, and nut \& bolt finders. Retailers offering photo printing services such as Costco, Meijer, and Walgreen offered a function allowing consumers to easily edit and order photos via their smartphone apps.

These results give practical guidance of the ways to use smartphone apps. First, U.S. retailers should not overlook any of the five key functions (i.e., content delivery, transaction, promotion, location service, and entertainment) in their smartphone apps in that all five key functions have been available in more than half of smartphone apps. In other words, consumers are used to the five key functions, and will expect to see the five key functions in smartphone apps provided by retailers.

\section{LIMITATIONS AND FUTURE RESEARCH}

Given the exploratory nature of this study, some limitations should be noted. First of all, top 100 U.S. retailers may not well represent the population of this study, all U.S. retailers. Although the study selected the top retailers because of their a large amount of budget and advanced marketing activities, some middle and small size retailers may well perform m-commerce activities using the smartphone. Future researchers may choose a large number of retailers randomly so that they can reflect the middle and small size retailers in the results. Moreover, although this study was just conducted to examine U.S. retailers, future studies can be conducted in other coun- 
tries in which the smartphone penetration rate is high, such as South Korea, Japan, and United Kingdom [24].

Second, the iPhone was used for examining top 100 U.S. retailers' smartphone apps. Although iPhone occupies more than half of the smartphone market [20], some smartphone apps not available in iPhone App Store can be possibly available in the other platform, Android. Future studies combining two platforms, iPhone and Android, may benefit retailers having more accurate information about smartphone functions provided by the top 100 U.S. retailers.

\section{REFERENCES}

[1] I. III. Clarke, "Emerging value proposition for m -commerce," $J$. of Bus. Stat, vol. 18, pp. 133-148, 2001

[2] S. Acharya, "Worldwide mobile cellular subscribers to reach 4 billion mark late 2008," Int. Telecommun.Union, 2008.

[3] P. Mahatanankoon, H. J. Wen, and B. Lim, "Consumer-based mcommerce: Exploring consumer perception of mobile applications," Comput. Standards \& Interfaces, vol. 27, pp. 347-357, April, 2005. http://dx.doi.org/10.1016/j.csi.2004.10.003

[4] M. Raento, A. Oulasvirta, and N. Eagle, "Smartphones: An emerging tool for social science," Sociol. Methods \& Research, vo. 37, pp. 423-454, February, 2009. http://dx.doi.org/10.1177/ 0049124108330005

[5] The Mobile Economy [Accessed 3 January 2016]. Available: http://www.gsmamobileeconomy.com/GSMA Global Mobile Ec onomy_Report_2015.pdf

[6] S. J. Barnes, "The mobile commerce value chain: Analysis and future developments," Int. J. of Inform. Manage, vol. 22, pp. 91108, 2002. http://dx.doi.org/10.1016/S0268-4012(01)00047-0

[7] U. Varshney and R. Vetter, "Mobile commerce: Framework, applications and networking support," Mob. Netw. Appl., vol. 7, pp.185-198, 2002. http://dx.doi.org/10.1023/A:1014570512129

[8] F. Adachi, "Wireless past and future: Evolving mobile communication systems," Fundamentals, vol. 84, pp. 55-60, January, 2001.

[9] F. Buellingen and M. Woerter, "Development perspectives, firm strategies and applications in mobile commerce," J. of Bus. Research, vol. 57, pp. 1402-1408, December, 2004.

[10] O. Kharif (2010). Smartphone use on the web goes mainstream. Available: http://www.bloomberg.com/news/articles/2010-0707/smartphone-use-on-the-web-goes-mainstream

[11] G. D. Abowd, L. Iftode, and H. Mitchell, "Guest editors' introduction: The smart phone--a first platform for pervasive computing," Pervasive Computing, vol. pp. 18-19, January, 2005.

[12] R. Jana. (2009). Retailers are learning to love smartphones. Available: http://www.businessweek.com/magazine/content/09 43/b4152049 042298.htm

[13] J. Kyrnin (2012). Writing a mobile friendly website: Mobile devices may be small, but they still need web design. Available: http://webdesign.about.com/od/mobile/a/write-a-mobile-friendlywebsite.htm

[14] N. Corasaniti. (2010). How do people use their smartphones? Available: http://bits.blogs.nytimes.com/2010/09/14/report-looksat-trends-with-mobile-apps

[15] G. L. Lohse and P. Spiller, "Electronic shopping," Commun. ACM, vol. 41, pp. 81-87, July, 1998. http://dx.doi.org/10.1145/278476. 278491

[16] J. Ho, "Evaluating the World Wide Web: A global study of commercial sites," J. of Comput.-Mediated Commun, vol. 3, pp. 0-0, June, 1997.

[17] R. Ström, M. Vendel, and J. Bredican, "Mobile marketing: A literature review on its value for consumers and retailers," $J$. of Retailing and Consumer Services, vol. 21, pp. 1001-1012, November, 2014.

[18] P. C. Verhoef, S. A. Neslin, and B. Vroomen, "Multichannel customer management: Understanding the research-shopper phenomenon', Int. J. of Research in Marketing, vol. 24, pp. 129-148, June, 2007. http://dx.doi.org/10.1016/j.ijresmar.2006.11.002

[19] Top 100 Retailers Chart 2015 [Accessed 5 January 2016] Available: https://nrf.com/2015/top100-table

[20] J. West and M. Mace, "Browsing as the killer app: Explaining the rapid success of Apple's Iphone," Telecommun. Policy, vol. 34, pp. 270-286, June-July, 2010. http://dx.doi.org/10.1016/j.telpol. $\underline{2009.12 .002}$

[21] T. Mikkonen and A. Taivalsaari, "Apps vs. open web: The battle of the decade," in Proceedings of the 2nd Workshop on Software Eng. for Mobile Applicat. Develop, 2011, pp. 22-26.

[22] A. K. Ghosh and T. M. Swaminatha, "Software security and privacy risks in mobile e-commerce," Commun. ACM, vol. 44, pp. 51-57, February, 2001. http://dx.doi.org/10.1145/359205.359227

[23] W. Knight, "A smart phone?," Infosecurity, vol. 6, pp. 32-35, November, 2009. http://dx.doi.org/10.1016/S1742-6847(09)70 $\underline{040-0}$

[24] H. Verkasalo, "A cross-country comparison of mobile service and handset usage," M.S. thesis, Dept. of Elect. and Commun. Eng. Networking Laboratory, Helsinki Univ. of Technology, 2007.

\section{AUTHOR}

W. Koo, Ph.D. is an assistant professor at Western Illinois University, Macomb, IL 61455, USA (e-mail: wkoo@wiu.edu ).

Submitted 06 May 2016. Published as resubmitted by the authors 13 June 2016. 